\title{
Triangulasyon yöntemiyle vazoepididimostomi deneyimimiz
}

\author{
Our vasoepididymostomy experience with triangulation method
}

\author{
Zafer Tokatlı1®, Kaan Aydos²®
}

öz

AMAÇ: Epididimal obstrüksiyon nedeniyle azoospermi gelişen olgularda, ejakülasyonda sperm elde etmek amacıyla modifiye 2 -sütür ile iç içe geçme tekniği kullanarak yaptığımız uç-yan vazoepididimostominin sonuçlarını sunmak.

GEREÇ ve YÖNTEMLER: Nisan 2015 ve Temmuz 2018 tarihleri arasında, epididimal obstrüksiyona bağlı azoospermi tanısıyla mikrocerrahi vazoepididimostomi (MVE) yaptığımız altı infertil hastanın verilerini değerlendirdik. Hastaların altı hafta arayla yapılan iki sperm analizinde semen volümünün ve $\mathrm{pH}$ 'sının normal olduğu ve azoospermi bulundugu teyit edildi. Fizik muayenede testislerden en azından birisi normal volümde, vaz deferensin intakt ve palpasyonda epididimin ise dolgundu. Plazma FSH düzeyi normal sınırlardaydı. Genel anestezi altında, cerrahi mikroskop kullanılarak iki adet çift iğneli 10/0 prolen sütür yardımıyla modifiye iç içe geçme tekniği kullanılarak epididim ile vaz deferens uç-yan anostomoz edildi. İșlem sadece tek taraflı olarak yapıldı ve cerrahi sonrası 1., 3. ve 6. aylardaki sperm parametreleri değerlendirildi. Ejakülatta sperm varlığı anostomoz başarısı olarak kabul edildi.

BULGULAR: Hastaların yaş ortalaması 29 (23-44) olup üçünde (\%50) epididimal obstrüksiyon geçirilmiş enfeksiyona bağlı iken, bir (\%17) hastada çocukluk çağında bilateral hidroselektomi öyküsü vardı. İki (\%33) hastada ise etiyoloji tespit edilemedi. Opere edilen toplam alt olgunun üçünde (\%50) ejakülatta motil sperm çıkışı sağlandı. Cerrahiyi takiben iki olguda 3. ayda, bir olguda ise 6. aydaki kontrollerinde sperm çıkışı olduğu tespit edildi. Ejakülatta çıkan total sperm sayısı ortalama $2 \times 106(1-3,4 \times 106)$ olup, ortalama motilite \%30 (\%10-\%40) olarak bulundu. Ejakülatta sperm çıkan olgulardan ikisinde etiyoloji enfeksiyona bağlı iken, birinde idiyopatik idi.

SONUÇ: Epididimal obstrüksiyona sekonder azoospermisi bulunan infertil erkeklerde transvers pozisyonda çift iğneli 2 adet sütür yerleștirilerek iç içe geçme tekniği ile yapılan vazoepididimostomi; teknik kolaylı̆̆ı, anastomoz sağlamlığı ve erken dönemde sperm çıkıșı sağlaması bakımından güvenilir ve etkili bir teknik olarak görülmüştür. Ancak daha kesin kanıya varmak için daha geniş serilerde ve diğer tekniklerle karşılaştırmalı çalışmalara ihtiyaç olduğu kanısındayız.

Anahtar Kelimeler: Epididimal obstrüksiyon, obstrüktif azoospermi, vazoepididimostomi

\section{ABSTRACT}

OBJECTIVE: To present the results of end-to-side vasoepididymostomy performed with tubular invagination technique by placing 2 doubleneedle sutures to obtain sperm in ejaculation in cases with azoospermia due to epididymal obstruction.

MATERIAL and METHODS: We evaluated the data of 6 infertile patients who underwent microsurgical vasoepididymostomy (MVE) with the diagnosis of azoospermia due to epididymal obstruction between April 2015 and July 2018. It was confirmed that the semen volume and $\mathrm{pH}$ were normal and azoospermia was found in the two sperm analysis performed six weeks apart. Under general anesthesia, an end-to-side anostomosis of the epididymis and the vas deferens was performed using a modified tubular invagination technique using 2 double-needle $10 / 0$ prolene sutures using a surgical microscope. The sperm parameters at 1,3 and 6 months after surgery were evaluated. The presence of sperm in the ejaculate was considered an anostomosis success.

RESULTS: The mean age of the patients was 29 (23-44). Motile sperm were obtained in the ejaculate in $3(50 \%)$ of 6 patients who underwent MVE. Sperm were obtained in 3 months postoperatively in 2 patients and in 6 months postoperatively in one patient. The mean total sperm count obtained from the ejaculate $2 \times 106(1-3.4 \times 106)$, and the mean motility was found to be $30 \%(10 \%-40 \%)$. While the etiology was related to infection in two of the cases where sperm was obtained from the ejaculate, one was idiopathic.

CONCLUSION: Vasoepididymostomy performed with tubular invagination technique by placing 2 double-needle sutures in transverse position in infertile men with azoospermia secondary to epididymal obstruction; It has been seen as a safety and effective technique in terms of technical ease, anastomosis stability and providing sperm retrieval in the early period. However, we think that studies in larger series and comparative studies with other techniques are needed to reach a more definite conclusion.

Keywords: Epididymal obstruction, obstructive azoospermia, vasoepididymostomy
'Özel Çankaya Yaşam Hastanesi Üroloji Kliniği, Ankara, Türkiye

${ }^{2}$ Ankara Üniversitesi Tıp Fakültesi, Üroloji Anabilim Dalı, Ankara, Türkiye

Yazışma Adresi/ Correspondence:

Uzm. Dr. Zafer Tokatlı

Özel Çankaya Yașam Hastanesi, Üroloji Servisi, 06610, Ankara, Türkiye

Tel: $\quad+903125082258$

E-mail: zafertokatli@yahoo.com

Geliş/ Received: 18.01.2021

Kabul/ Accepted: $\quad 09.02 .2021$

\section{Giriș}

İnfertil erkeklerin $\% 15^{\prime}$ inde azoospermi tespit edilir. Bunların da \%40'ında epididim, vaz deferens veya ejakülatör kanal düzeyinde obstrüktif bir patoloji söz konusudur. [1] Epididimal seviyedeki obstrüktif azoosperminin (OA) etiyolojisinde pelvik-skrotal travma ve epididimal enfeksiyonlara sık rastlanılır. Daha nadir olarak da tekniğine 
uygun yapılmayan hidroselektomi cerrahisi, perkütan epididimal sperm aspirasyonu (PESA) veya mikrocerrahi epididimal sperm aspirasyonu (MESA) gibi iyatrojenik nedenler sorumludur. Günümüzde infertilite tedavisinde yardımcı üreme tekniklerinin yaygın olarak kullanılması ve infertil çiftlerin daha kısa sürede çocuk sahibi olma gibi istekleri nedeniyle OA'nın düzeltilmesine yönelik cerrahi yöntemler biraz geri planda kalmaktadır.

Azoosperminin epididimal obstrüksiyona bağlı olduğu düşünülen olgularda kalıcı sperm çıkışı sağlanması için öncelikli olarak mikrocerrahi vazoepididimostomi (MVE) düşünülmelidir. Testis biyopsisinde spermatogenezin normal olduğu ya da ameliyat sırasında epididimal örnekte canlı sperm bulunan ve buna ek olarak distalde vaz deferensin ve ejakülatör kanalın açı olduğu olgularda vazoepididimostomi endikedir. ${ }^{[2]}$ MVE işlemi sırasında sperm elde etmek ve saklamak, vazoepididimostominin başarısız olduğu olgularda ileride yapılacak invitro fertilizasyon/intrastoplazmik sperm enjeksiyonu (IVF/ICSI) için gerekli olabilir. ${ }^{[3]}$ Epididimal tubul çapının çok küçük olması $(0,2 \mathrm{~mm})$ ve duvarının inceliği nedeniyle erkek üreme sisteminde yapılan mikrocerrahi girişimler arasında vazoepididimostomi en zor ameliyat tekniği olarak kabul edilir. ${ }^{[4]}$ Vazoepididimostomi için günümüze kadar değişik teknikler tanımlanmış olmakla birlikte en sık kullanılanları uç-uç, uç-yan ve uç-yan iç içe geçme (intussusception) teknikleridir. ${ }^{[-7]}$

İç içe geçme tekniği ilk olarak Berger tarafından tanımlanmış olup, triangulasyon tekniği olarak da bilinir. Diğer tekniklere göre daha az sütür ile yeteri kadar sağlam anastomozun sağlanabilmesi ve kanama azlığı en önemli avantajıdır. Ancak, her ne kadar erken serilerde umut verici sonuçlar bildirilmiş olsa da bu yöntemde de bazı teknik sorunlarla karşılaşılmıştır. Üç sütür yerleştirilerek yapılan orijinal iç içe geçme tekniğinde, ilk sütürün yerleştirilmesi sırasında seminal sıvı sızmasına bağlı tüpte kollaps gelişmesi ve sütürler arasından güçlükle yapılabilen tubülotomi sırasında sütürlerden birinin yanlışlıkla kesilebilmesi tekniğin öne çıkan dezavantajlarıdır. Bunun üzerine Marmar tarafından triangulasyon iç içe geçme tekniği yerine, eş zamanlı çift iğne yerleştirme şeklinde modifiye bir teknik tanımland.. ${ }^{\left[{ }^{[]}\right.}$

Biz bu çalışmada, modifiye 2-sütür ile iç içe geçme tekniği kullanarak yaptığımız uç-yan vazoepididimostomi sonuçlarımızı sunmayı amaçladık.

\section{GEREÇ ve YÖNTEMLER}

Çalışmaya, Nisan 2015 ve Temmuz 2018 tarihleri arasında, epididimal obstrüksiyona bağlı azoospermi nedeniyle modifiye 2-sütür ile iç içe geçme tekniği kullanarak MVE yaptığımız altı infertil hasta dâhil edildi. Olgularda altı hafta arayla yapılan iki sperm analizinde semen volümünün ve $\mathrm{pH}$ 'sının normal olduğu ve azoospermi bulunduğu teyit edildi. Fizik muayenede testislerden en azından birisi normal volümde ve vaz deferens intaktı. Ayrıca epididim dolgun olarak palpe edildi. Hastaların plazma FSH düzeyleri normal sınırlardayd. Erkeklerin hepsinde eşlerinin detaylı jinekolojik değerlendirmeleri yapıldı ve normal oldukları ortaya konuldu. Vazoepididimostomi ya da girişimsel yolla sperm elde edilerek üremeye yardımcı teknikler uygulanabileceği ile ilgili seçenekler sunuldu ve hastalardan anastomoz yapılması yönünde onayları alındı. Olguların hiç birisinde vazektomi ya da pelvik cerrahi öyküsü bulunmuyordu.

Genel anestezi altında anastomozun yapılacağı taraftan skrotal kesi yapılarak testis ve spermatik kord kesi dışına alındı. Önce vaz deferens diseke edilerek proksimal kısmına yarım transver insizyon yapıldı ve serum fizyolojik enjeksiyonu ile vaz deferensin distal kısmının açık olduğu kontrol edildi. Bu sırada proksimal vaz ucundan seminal sıvı gelmediği ve epididim tubüllerinin ileri derecede dilate olduğu görüldü.

Cerrahi mikroskop ile $\times 25$ büyütme altında önce epididim üzerinde anastomozun yapılacağı dilate tubül saptandı ve tubül üzerindeki adventisiya mikro bistüri yardımıyla kesilerek bir pencere oluşturuldu. Vaz deferensin distal ucu, seromusküler tabakasından geçirilen $8-0$ prolen sütürle epididim adventisiyasına yaklaştırıldı.

Anostomozun yapılacağı epididimal tubülü ortaya çıkarmak için epididim hafifçe komprese edildikten sonra iki adet çift iğneli 10/0 prolen sütür Marmar'ın tekniğinde tanımladığı şekilde tubül üzerinde transvers ve birbirlerine paralel şekilde geçirildi. (Şekil 1a). İki iğne arasında, micro bistürinin ucunun geçmesine yetecek genişlikte bir aralık kalmasına dikkat edildi. Daha sonra sütürler dışa doğru hafifçe gerdirilerek mikro bistüri ile epididimotomi yapıldı. Bu sırada sızan epididimal sıvı steril bir lam üzerine alınarak laboratuvar mikroskobunda sperm varlığını göstermek için incelendi. Arkasından dört adet iğne ucu vaz deferensin lümeninden içten dışa doğru geçirildi ve sütürler gerildiğinde epididimal tubülün vaz deferens lümeninine doğru çekildiği görüldü (Şekil 1b).

Vaz deferens üzerindeki $8 / 0$ prolen sütürle epididim adventisiyasına tespit edildikten sonra, $10 / 0$ vasoepididimal anostomoz sütürleri dikkatli bir şekilde sıkıca bağlandı (Şekil 1c). İşlem sırasında anastomoz üzerinde bir gerginlik oluşmamasına dikkat edildi. Vaz deferensin seromusküler tabakası ile epididim adventitiasına üç adet ilave sütür konularak anastomoz desteklendi. Epididimal sıvida sperm bulunmayan olgularda başka bir dilate epididimal tubül ile işlem tekrarlandı. Ameliyatın ertesi günü hastalar taburcu 

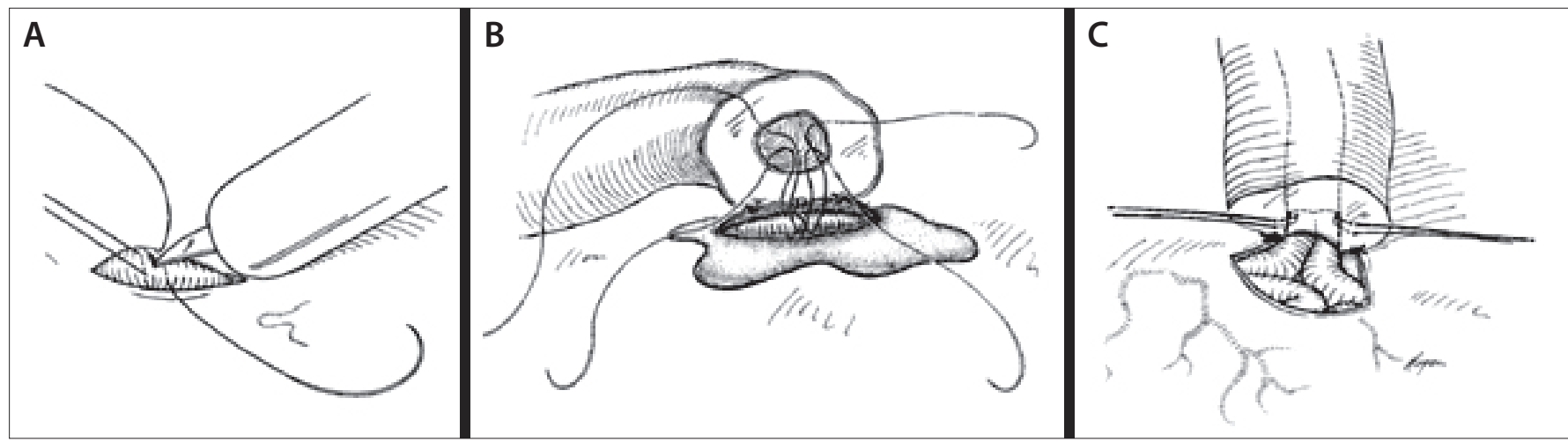

Şekil 1. İki adet çift iğneli 10-0 prolen sütür epididim duvarına transvers şekilde yerleştirildikten sonra arasından epididimotomi yapılır (a). Daha sonra iğneler vaz duvarına, lümenden dışa doğru geçirilir (b). Sütürler, düğüm lümenin dışında kalacak şekilde bağlanır ve vazın kas tabakası içinde kalacak şekilde gömdürülür (c). (Marmar, 2000)

edildi ve dört hafta süreyle ejakulasyon yapmamaları önerildi. Ameliyatı takiben 1., 3. ve 6. aylardaki ejakülat sonuçları değerlendirildi ve ejakülatta motil sperm varlığı başarı olarak kabul edildi.

\section{BULGULAR}

Epididimal obstrüksiyondan şüphe edilen toplam 6 azoospermik erkeğe modifiye 2-sütür ile iç içe geçme tekniği kullanılarak uç-yan vazoepididimostomi yapıldı. Hastaların yaş ortalaması 29 (23-44) idi. Hastaların üçünde (\%50) epididimal obstrüksiyon geçirilmiş enfeksiyona bağlı iken, bir (\%17) hastada çocukluk çağında bilateral hidroselektomi öyküsü vardı. İki (\%33) hastada ise etiyoloji tespit edilemedi. Olguların hepsinde de tek taraflı anastomoz yapild 1 .

Opere edilen toplam altı olgunun üçünde (\%50) ejakülatta motil sperm çıkışı sağlandı. Cerrahiyi takiben iki olguda 3. ayda, bir olguda ise 6. aydaki kontrollerinde sperm çıkışı olduğu tespit edildi. Ejakülatta çıkan total sperm sayısı ortalama $2 \times 10^{6}\left(1-3,4 \times 10^{6}\right)$ olup, ortalama motilite \%30 (\%10- \%40) olarak bulundu. Ejakülatta sperm çıkan olgulardan ikisinde etiyoloji enfeksiyona bağlı iken, birinde idiyopatikdi. Postoperatif dönemde iki olguda lokal cilt ekimozu gelişmiş olup, bir hafta içerisinde tamamen kayboldu. Bunun dışında ciddi bir komplikasyon görülmedi.

\section{SONUÇ}

Epididim seviyesinde tıkanıklığa bağlı azoospermi olgularının tedavisinde vazoepididimostomi uygulaması vaz lümeni ve epididim lümeni arasında cerrahi anastomoz tekniğini gerektirir. Bu teknik ilk olarak uç-uca ve uç-yan anastomoz şeklinde yapılmıştır. ${ }^{[5,7]}$ İç içe geçme tekniği ise daha sonra tanımlanmıştır. Bu tekniğin güvenilirliliği, ilk olarak Stefanovic ve ark. tarafından ratlar üzerinde gösterilmiştir. ${ }^{\left[{ }^{[0]}\right.}$ Anastomozun histolojik incelemeleri, vaz lümenine geçen epididim tubülünün tamamen rezorbe olduğunu ve su geçirmez bir iyileşmenin gerçekleştiğini, bu şekilde güvenilir bir lümen açıklığı sağlanabileceğini ortaya koymuştur. Bunu takiben içiçe geçme tekniği ile anastomozlar daha yaygın olarak uygulanmaya başlanmıştır.

1998 yılında Berger epididim tubülü üzerine üç köşeden çift iğneli 3 sütür yerleştirerek ilk kez tubüler içiçe geçme tekniği ile uç-yan triangulasyon vazoepididimostomi tekniğini yaptı ve \%92 teknik başarı bildirdi. Aynı tekniği kullanarak vazoepididimostomi yapılan diğer bir çalışmada da \%84 başarı bildirilmiştir. ${ }^{[10]}$ Daha sonra Marmar, çift iğneli iki adet sütürü tubüle transvers yerleştirerek iç içe geçme tekniğini gerçekleştirdi ve \%77 sperm çıkışı elde etti. ${ }^{[8]}$ Bunu takiben iç içe geçme tekniği, sütürlerin tubül üzerine longitudinal yerleştirilmesi ile modifiye edilerek kullanıldı ve $\% 59$ sperm çıkışı sağlandı. ${ }^{[11]}$ Sütürlerin longitudinal yerleştirilmesinin, tubül üzerinde daha geniş bir açıklık sağlayacağı ve böylece anastomozun kapanma olasılığının azalacağı belirtilmiştir. İç içe geçme tekniği bu çalışmalarda çift iğneli 10-0 naylon sütürlerle yapılmıştır. Ancak tek iğneli sütürlerle de yapıldığı zaman, benzer neticelerin alınacağı da bildirilmiştir Burada önce vaz lümeninde mukozal tabakadan dıştan içe sütür geçirilmekte ve aynı sütür daha sonra epididim duvarından ve arkasından da tekrar vaz lümeninde içten dişa geçirilerek anastomoz gerçekleştirilmekte. Bu şekilde yaptıkları 17 olguda, Zhao ve ark. $\% 58,8$ başarı elde etmiştir. ${ }^{[12]}$

İç içe geçme tekniği tek sütür kullanılarak da yapilabilir. Shekarriz ve Pomer 11-0 naylon sütürü önce vaz lümeninden, daha sonra epididimden ve nihayet tekrar vaz lümeninden dışa doğru geçirmiş ve sütürün aksi tarafından epididim tubülünü açmışlardır. ${ }^{[13]}$ Böylelikle epididim vaz lümenine iki noktadan tespit edilmiş olur. Bu çalışmada $\% 80$ anastomoz açıklığı bildirmişlerdir. Bu da göstermektedir ki, sütür sayısı anastomoz sağlamlığı üzerinde tek başına bir faktör değil. 
Bu çalışmada biz çift iğneli iki sütürü epididim tubülünden transvers geçirdik ve vaz lümenine dört noktadan tespit etmiş olduk. Bunun getirdiği bazı avantajlar vardı. İç içe geçme tekniğinin orjinalinde tanımlanan üç sütürlü trinagulasyona göre iki sütür yerleştirilmesi anastomoz tekniğine büyük kolaylık getirmektedir. Trinagulasyon tekniğinde üç sütür ile epididim üzerinden üç köşeli bir pencere açılması sırasında, ilk yerleştirilen sütürün kenarından sızan epididimal sıvı, görüş alanını kapatarak, diğer sütürlerin sağlıklı yerleştirilmesini engelleyebilmektedir. Bunu önlemek için Goldstein, tubül içine yerleştirilen sütürlerin yerinde bırakılarak çıkarılmamasını, lümende pencere açıldıktan sonra çıkarılmasını önermiştir. ${ }^{[2]}$ Biz de ikinci sütürü yerleştirene kadar diğerini yerinde bıraktık. Böylece epididimal sıvı sızıp, lümende kollaps gelişmeden önce sütür yerleştirme işlemi tamamlanmış oldu. Marmar kendi tekniğinde, her iki sütürü de iğneleri aynı portekü ile tutarak aynı anda yerleştirmektedir. Ancak 10-0 iğnelerin çok ince olması, portekü ağzında iki iğnenin birbirine tam paralel tutulmasını zorlaştırmakta. Biz, ilki yerinde bırakılarak ayı ayrı epididimden geçirilmesinin ameliyatı daha kolaylaştırdığı kanısındayız.

Ameliyatta iğneleri tubül eksenine transvers şekilde yerleştirmek, longitudinal yerleştirmeye göre daha rahat olmakta. Bizim önceki tecrübelerimizde, longitudinal yerleştirilen sütürler arasından epididimotomi yapılırken sütürlerin kesilme tehlikesi karşımıza çıkıyordu. Oysa transvers yerleştirilen iki sütürün arasından epididim duvarının kesilmesi daha güvenilir olmakta. Yeterli lümen açıklığının oluşturulmasında hangi tekniğin daha üstün olduğu konusunda bir kanıya varmak içinse, daha fazla sayıda olgu üzerinde karşılaştırmalı çalışmalara ihtiyaç olduğu kanısındayız.

Çift iğneli sütür kullanılması, tek iğneli olandan daha avantajlıdır. Tek iğneli sütürlerde aynı iğnenin iki kez kalın vaz duvarından ve bir kez de epididimden geçirilmesi sırasında iğnede eğilme hatta sütürde kopma riski taşımakta. Ayrıca manipülasyon da daha güç olmakta. Epididim tubülünden iki sütür geçirilerek yapılan bu teknikte tubül vaz duvarına dört noktadan sabitlenebilir. Uç-uca ya da uç-yan şeklinde yapılan anastomozlarda tubülü dört noktadan sabitlemek için 4 ayrı sütür yerleştirilmesi gerekirken, bu teknikte sadece iki sütür ile dört nokta sabitliği elde edilebilmektedir. Sütürler vaz duvarının kas tabakası üzerinde kalacak şekilde bağlandığı için, düğümlerin lümeni engelleme riski de olmamakta ve dokuya gömülü kalabilmektedir.

Serimizde sperm çıkışı olguların \%50'sinde sağlandı. Bu, iç içe geçme tekniği kullanılan diğer serilere göre düşük olarak görülmektedir. Marmar serisinde \%87,5 teknik başarı bildirmektedir. Ancak bu çalışmada olgular vazektomi düzeltilmesine giren toplam 19 erkek arasından seçilmiş olup, çift taraflı anastomoz yapılmış dokuz olguya ait verilerdir. ${ }^{[8]}$ Biz olguların özelliğinden dolayı tek taraflı anostomoz yaptık. Olgularımızın yarısı enfeksyona bağlı, biri de geçirilmiş skrotal cerrahiden sonra gelişen tıkanıklık olduğundan dolayı, anastomoz da güç oldu. Binsaleh, tek taraflı iç içe geçme tekniği kullanarak vazoepididimostomi yaptığı olgularda başarısını $\% 50$ olarak bildirmektedir. ${ }^{[11]}$ Bunu da olguların \%64'ünün enfeksiyona bağlı tıkanıklık olması ile ilişkilendirmektedir. Dolayısıyla, enfeksiyona ya da geçirilen skrotal ameliyatlara bağlı obstrüktif azoospermi olgularının sonuçlarının diğerlerine göre daha düşük olması beklenilen bir sonuçtur.

Bizim çalışmamızda hasta takip süresi altı aydı. Bu, sperm çıkışı için kısa bir zaman aralığıdır. Diğer serilerde hasta takip süreleri en az 12 ay olarak bildirilmiştir. ${ }^{[8,11]}$ Takip süresi ve sperm kontrolleri ne kadar fazla olursa, sperm çıkma oranlarında da artış beklenebilir.

Başlangıçta sperm çıkışı sağlanan VE olgularında ileri dönemlerde sekonder azoospermi gelişebilir; 6-14 aylik takiplerde geç dönem anastomoz darlıklarının gelişimi \%1-14 olarak bildirilmiştir. ${ }^{[14]}$ Süre uzadıkça bunun sıklığ̆ da artmakta ve 24. ayda \%18'e ulasabilmektedir ${ }^{[10]} ; 3-30$ aylik takiplerde doğal yolla gebelik oranlar ise \%30-40 arasinda görülmektedir. ${ }^{[15]}$ Bizim olgularımızda altı aylık takip sürecinde doğal yolla gebelik görülmedi.

Sonuç olarak, epididimal seviyede obstrüktif azoospermisi bulunan infertil erkeklerde transvers pozisyonda çift iğneli iki adet sütür yerleştirilerek içiçe geçme tekniği ile yapılan vazoepididimostomi, teknik kolaylığı, anastomoz sağlamlığı ve erken dönemde sperm çıkışı sağlaması bakımından güvenilir ve kullanışlı bir teknik olarak görülmüsstür. Ancak daha kesin kanıya varmak için daha geniş serilerde ve diğer tekniklerle karşılaştırmalı çalışmalara ihtiyaç olduğu kanısındayız.

Hakem Değerlendirmesi

Dış bağımsız.

Çıkar Çatışması

Yazarlar çıkar ilişkisi olmadığını beyan etmişlerdir.

Finansal Destek

Herhangi bir mali destek alınmamıştır.

Peer-review

Externally peer-reviewed.

Conflict of Interest

No conflict of interest was declared by the authors.

Financial Disclosure

No financial support has been received. 


\section{KAYNAKLAR}

1. Wosnitzer M, Goldstein M, Hardy MP. Review of azoospermia. Spermatogenesis 2014; 4:e28218. [CrossRef]

2. McDougal WS, Wein AJ, Kavoussi LR, Partin AW, Peters CA. Campbell-Walsh Urology, 11th ed. Review E-Book: Elsevier Health Sciences; 2015.

3. Schrepferman CG, Carson MR, Sparks AE, Sandlow JI. Need for sperm retrieval and cryopreservation at vasectomy reversal. J Urol 2001;166:1787-9. [CrossRef]

4. Goldstein M, Tanrikut C. Microsurgical management of male infertility. Nat Clin Pract Urol 2006;3:381-91. [CrossRef]

5. Thomas Jr A. Vasoepididymostomy. Urol Clin North Am 1987;14:527-38. [CrossRef]

6. Berger RE. Triangulation end-to-side vasoepididymostomy. J Urol 1998;159:1951-3. [CrossRef]

7. Wallach E, Silber SJ. Vasectomy and vasectomy reversal. Fertil Steril 1978;29:125-40. [CrossRef]

8. Marmar JL. Modified vasoepididymostomy with simultaneous double needle placement, tubulotomy and tubular invagination. J Urol 2000;163:483-6. [CrossRef]

9. Stefanovic KB, Clark SA, Buncke HJ. Microsurgical epididymovasostomy by tubule intussusception: a new technique in rat model. Fertil Steril 1991;55:189-93. [CrossRef]
10. Schiff J, Chan P, Li PS, Finkelberg S, Goldstein M. Outcome and late failures compared in 4 techniques of microsurgical vasoepididymostomy in 153 consecutive men. J Urol 2005;174:651-5. [CrossRef]

11. Binsaleh S. Two-suture single-armed longitudinal intussusception vasoepididymostomy for obstructive azoospermia: report of patients characteristics and outcome. Int Urol Nephrol 2014;46:2271-7. [CrossRef]

12. Zhao L, Deng C-H, Sun X-Z, Chen Y, Wang W-W, Zhao L-Y, et al. A modified single-armed technique for microsurgical vasoepididymostomy. Asian J Androl 2013;15:79-82. [CrossRef]

13. Shekarriz M, Pomer S. Microsurgical vasoepididymostomy: a comparison between the end-to-side anastomosis and the invagination technique. Urol Res 1991;19:285-7. [CrossRef]

14. Farber NJ, Flannigan R, Li P, Li PS, Goldstein M. The kinetics of sperm return and late failure following vasovasostomy or vasoepididymostomy: a systematic review. J Urol 2019;201:24150. [CrossRef]

15. Shiraishi K, Matsuyama H. Outcomes of partial intussusception and endo-to-side vasoepididymostomy in men with epididymal obstructive azoospermia. Int J Urol 2020;27:1124-9. [CrossRef] 